\title{
East London's Homeless: a retrospective review of an eye clinic for homeless people
}

Penny J. D'Ath ${ }^{1 *}$, Laura J. Keywood ${ }^{2}$, Elaine C. Styles ${ }^{3}$ and Clare M. Wilson ${ }^{4}$

\begin{abstract}
Background: There is very little published work on the visual needs of homeless people. This paper is the first study to investigate the visual needs of homeless people in the UK. Although similar work has been done in other countries, this study is unique because the United Kingdom is the only country with a National Health Service which provides free healthcare at the point of access. This study analysed the refractive status of the sample used, determined the demographics of homeless people seeking eye care and established if there is a need for community eye health with access to free spectacle correction in East London.

Methods: This retrospective case study analysed the clinical records of 1,141 homeless people using the Vision Care for Homeless People services at one of their clinics in East London. All eye examinations were carried out by qualified optometrists and, where appropriate, spectacles were dispensed to patients. Data captured included age, gender, ethnicity and refractive error. Results were analysed using two-sample t-tests with Excel and Minitab.

Results: Demographics of age, gender and ethnicity are described. Spherical equivalents (SE) were calculated from prescription data available for 841 clinic users. Emmetropia was defined as SE-0.50DS to +1DS, myopia as SE $<-0.50 D S$, and hyperopia as SE $>+1 D S$.

The majority of clinic users were male $(79.2 \%, n=923)$. Approximately $80 \%(n=583)$ of clinic users were white, $10 \%(n=72)$ were 'black', $4 \%(n=29)$ 'Asian' and the remaining $5.6 \%(n=40)$ were of 'mixed ethnicity' and 'other' groups. The mean age of females attending the clinic was significantly lower than that of males ( 45.9 years, $\mathrm{SD}=13.8 \mathrm{vs}$ ' 48.4 years, $\mathrm{SD}=11.8$ ) when analysed using a two-sample $t$-test ( $(317)=$ $2.44, p=0.02$ ). One third of service users were aged between 50-59 years. Myopia and hyperopia prevalence rates were $37.0 \%$ and $21.0 \%$ respectively. A total of $34.8 \%$ of homeless people were found to have uncorrected refractive error, and required spectacle correction.
\end{abstract}

Conclusions: This study has identified a high proportion of uncorrected refractive error in this sample and therefore a need for regular eye examinations and provision of refractive correction for homeless people.

Keywords: Optometry, Eye care, Homeless people, Ophthalmology

\section{Background}

Homelessness has been described as a "shameful national problem" [1]. It is estimated that there are approximately 310,000 to 380,000 single homeless people in England [2]; the majority of whom are male [3]. There are also a significant number of homeless families including an estimated 116,000 homeless children [3]. These numbers are on the rise. In 2014, the number of people sleeping on the

\footnotetext{
* Correspondence: penny.dath@gmail.com

'Division of Optometry and Visual Science, School of Health Sciences, City

University London, Northampton Square, London ECIV OHB, UK

Full list of author information is available at the end of the article
}

streets in London increased by $75 \%$ over a four year period [4].

Whilst some homeless people resort to sleeping rough, a majority of homeless people live in hostels, squats, bed and breakfast accommodation and in insecure conditions with friends or family $[5,6]$. Due to their status, the overall health of homeless people tends to deteriorate due to the difficulties they face in accessing regular health care $[3,6,7]$. Homeless people are more likely to suffer from mental health disorders $[3,8,9]$, alcohol and substance abuse $[8,10]$ as well as less commonly encountered medical conditions such 
as HIV, hepatitis, diabetes [11], tuberculosis [12], peripheral vascular disease and skin disorders [1]. Homeless people also tend to have more eye problems than the general population. Previous studies have found that homeless people have higher rates of cataract, glaucoma and binocular vision problems [13] and are more likely to have uncorrected refractive error [11, 14]. Mortality rates are higher with an average life span of 42 years [3]. Homeless males are 8.3 times more likely to die than 18-24 year olds in the general population [15]. Despite these figures, homeless people are far less likely to receive medical interventions $[6,9]$ for reasons including being unable to provide a permanent address [16].

It is not clear how many homeless people have access to eye care as there is little information about the visual needs and visual problems encountered in this population. The studies aforementioned were carried out in North America where health care provisions and policies are different to those in the United Kingdom. As vision plays a significant role in quality of life [13], it is important to investigate the visual needs of this already vulnerable population.

Homelessness is a complex issue and varies in degree of severity. Beyond the traditional image of someone with "no fixed abode", which relates solely to rough sleepers and street homeless, an individual can be classified as homeless if they live in a hostel, B\&B or even sofa surfing (on friends and family members' couches) [5, 6]. For the purposes of this paper, the criterion used to classify a person as homeless was that the person must not have a fixed stable home.

This paper is the first study of the visual status of homeless people based in the UK.

\section{Aims}

The aims of the study were as follows:

- To analyse the refractive status of the sample used;

- Determine the demographics of homeless people seeking eye care in East London;

- Establish if there is a need for community eye health with access to free spectacle correction in East London.

\section{Methods}

\section{Study design}

This retrospective case study examined the clinical records of homeless people using the Vision Care for Homeless People (VCHP) services at one of their clinics in East London. The VCHP mission statement is "homeless and other vulnerable people" [17]. This could also include people who used to be homeless but now are in a flat, but their income is very low and circumstances are vulnerable. It is important to point out that of those homeless people who have been rehoused, a high number of these have lost their dwelling due to being unable to cope with these changes in circumstance. The charity helps these people too. It is, therefore, possible that a small minority of those using the charity have since been rehoused and are settled in their new accommodation but are still using the charity for their eye care. This issue is consistent with other research into homeless people in that any person (homeless or otherwise) may, for example, attend a soup kitchen or clinic intended for homeless users only regardless of whether they would fit into the homeless categories.

This charity offers full eye examinations but does not conduct eye screening events although it does provide education and advice. All eye examinations were carried out by qualified optometrists and where appropriate, spectacles were dispensed to patients. Details of 1,141 electronic records of eye examinations performed between 2003 and 2012 were transferred onto a new computer database, Optix, for analysis.

In order to make an estimation of the number of people who require spectacles, this study used previously determined figures that an uncorrected refractive error of $<=-1 \mathrm{DS}$ and $>=+5 \mathrm{DS}$ would result in vision of approximately $<=6 / 18[18,19]$.

In keeping with the Declaration of Helsinki (2000), ethical approval was obtained from the City University London Research and Ethical Committee.

\section{Data analysis}

Data captured included age, gender, date of visit and refractive error. Other data was not included as it was not on the database. Results were analysed using Excel and Minitab.

\section{Results}

A total of 1,141 records were analysed for demographic statistics and refractive error.

\section{Age}

The sample comprised of 903 males (79.2 \%) and 238 females $(20.8 \%)$.

Age details were recorded for 1,112 (97.5\%) of the sample (Table 1$)$. The mean age was 47.9 years $(\mathrm{SD}=12.3$; range: $22-87$ years). The mean age of females attending the clinic was significantly lower than that of males ( 45.9 years, $\mathrm{SD}=13.8$ vs' 48.4 years, $\mathrm{SD}=11.8$ ) when analysed using a two-sample $t$-test $(\mathrm{t}(317)=2.44, p=0.02$.

The most frequent age group attending were aged between 50 and 59 years old $(30.7 \%, 341 / 1,112)$, closely followed by the $40-49$ year olds $(26.6 \%, 295 / 1,112)$ of clinic users. More than $75 \%$ of patients fell into the 30-59 years old bracket $(851 / 1,112)$. VCHP rarely see people below 18 years of age in their clinics. 
Table 1 Ages of VCHP patients

\begin{tabular}{lccr}
\hline Age range & $M$ & \multicolumn{1}{l}{ Total } \\
& $N=884(79.5)$ & $N=228(20.5 \%)$ & $n=1,112(\%)$ \\
\hline Age range 19-29 & $50(5.7)$ & $29(12.7)$ & $79(7.1)$ \\
Age range 30-39 & $154(17.4)$ & $61(26.8)$ & $215(19.3)$ \\
Age range 40-49 & $248(28.0)$ & $47(20.6)$ & $295(26.6)$ \\
Age range 50-59 & $289(32.7)$ & $52(22.8)$ & $341(30.7)$ \\
Age range 60-69 & $109(12.3)$ & $27(11.8)$ & $136(12.2)$ \\
Age range 70-79 & $27(3.1)$ & $9(4.0)$ & $36(3.2)$ \\
Age range 80-89 & $7(0.8)$ & $3(1.3)$ & $10(0.9)$ \\
Total & 884 & 228 & $1,112(100.0)$ \\
\hline
\end{tabular}

\section{Ethnicity}

Ethnicity was recorded in $63 \%(724 / 1,141)$ of patients (Table 2). The records included are from the period 2003-2012 which may account for some of the missing data. Missing data is common in large data sets with Talbert et al. (2013) reporting that "up to $36 \%$ of eligible cases" have missing data [20]. Over four fifths (583/724) of the clinic users were 'white', $10 \%(72 / 724)$ were 'black', 4 \% (29/724) 'Asian' and the remaining $5.6 \%$ (40/ 724) were of 'mixed ethnicity' and 'other' groups. The 'white other' category includes people originating from countries apart from the UK or Ireland such as Europe.

\section{Number of eye examinations}

The number of homeless people using the service increased year on year over the study period, perhaps due to increased awareness of the new facility amongst the

Table 2 Ethnicity of VCHP patients

\begin{tabular}{lll}
\hline Ethnicity & $n=724$ & Total (\%) \\
\hline White Other & 355 & 49.0 \\
White British & 206 & 28.5 \\
Black/British-African & 45 & 6.2 \\
Black/British-Caribbean & 24 & 3.3 \\
White Irish & 22 & 3.0 \\
Asian/British-Other & 13 & 1.8 \\
Mixed White \& Black African & 10 & 1.4 \\
Asian/British-Indian & 10 & 1.4 \\
Other & 10 & 1.4 \\
Mixed Others & 8 & 1.1 \\
Chinese & 6 & 0.8 \\
Mixed White \& Black Caribbean & 4 & 0.6 \\
Asian/British-Pakistani & 3 & 0.4 \\
Asian/British-Bangladeshi & 3 & 0.4 \\
Black/British-Other & 3 & 0.4 \\
Mixed White \& Asian & 24 & 100.0 \\
Total & &
\end{tabular}

population and also due to the numbers of homeless people in London increasing [4] (Fig. 1). In addition, there has also been an increase in the number of clinics that VCHP can provide. The charity opened its first clinic in 2003 and since 2007 to the present date, the charity now has six clinics situated around England (Table 3).

\section{Visual function results}

The spherical equivalent (SE) was calculated from prescription data available for 841 clinic users (Fig. 2). The spherical equivalent, is defined as the sphere value plus half of the cylinder value in dioptre sphere (DS) [21]. In keeping with other studies, emmetropia was defined as SE-0.50DS to +1DS, myopia as $\mathrm{SE}<-0.50 \mathrm{DS}$, and hyperopia was as SE > +1DS [22].

There were no significant differences between right and left eye data when analysed using a two-sample $t$ test $(\mathrm{t}(1363)=0.04, p=0.97)$ and so right eye data was selected for analysis. Based on right eye data and excluding 'not known' data, the prevalences for emmetropia, myopia and hyperopia were $42.0 \%$ (353/841), $37.0 \%(311 / 841)$ and $21.0 \%(177 / 841)$ respectively.

Figure 2 shows a normal bell shaped distribution of refractive error. The prescription issued most frequently was between Plano and +1DS [Right eye: $27.6 \%$, 232/841; Left eye: $25.6 \%$, 216/841]. The second most frequent prescription was between Plano and-1DS [Right eye: $16.4 \%, 138 /$ 841; Left eye: $18.1 \%, 152 / 841$ ].

There were several occurrences $(n=51)$ of high refractive error of over +/-6DS; with the most hyperopic and myopic spherical equivalents prescribed being +17 DS and-21DS respectively. There were a total of 841 distance prescriptions issued and 504 of these included a near addition. It was not possible to calculate the number of actual dispenses from the data available.

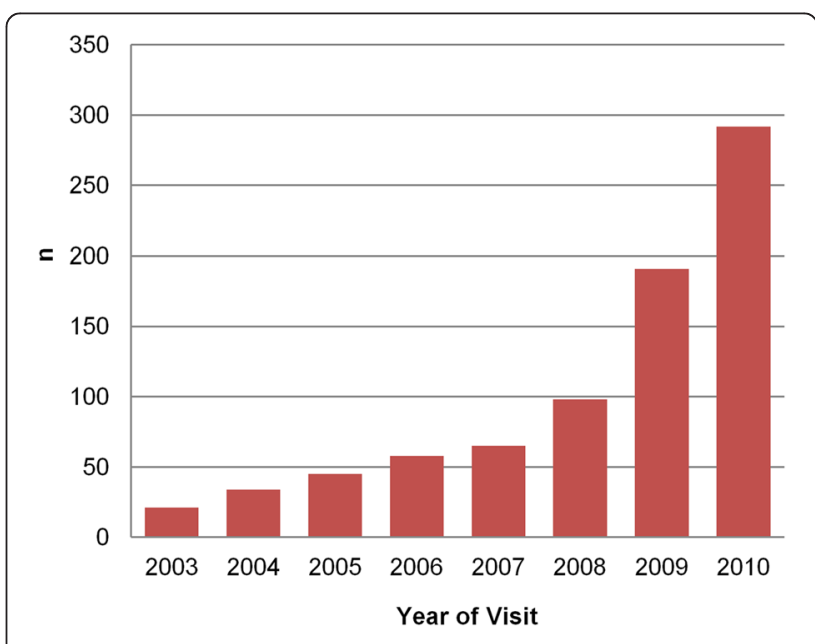

Fig. 1 Number of eye examinations each year at VCHP 
Table 3 Details of clinics run by Vision Care for Homeless People

\begin{tabular}{lll}
\hline Clinic & Location & Opening times \\
\hline Crisis Skylight & Liverpool Street, London, E1 & Mondays: $2.00-6.00$ pm \\
& & Wednesdays: $2.00-6.00$ pm \\
West London Day Centre & Marylebone, London, W1 & Mondays: $9.00-12.30$ pm \\
The Broadway Centre & Goldhawk Road, London, W12 & Wednesdays: $10.00-2.30$ pm \\
Birmingham & Birmingham, B9 & Mondays: $9.00-1.00$ pm \\
Brighton & Brighton, BN1 & Thursdays: $9.00-12.30$ pm \\
Manchester & Manchester, M15 & Mondays: $10.30-3.00$ pm \\
\hline
\end{tabular}

Unfortunately, the data on refractive error was not available for analysis for the entire sample of 1,141 patients, so it was not possible to investigate exact requirements for spectacle corrections. Using previously determined figures that an uncorrected refractive error of $<=-1 \mathrm{DS}$ and $>=+5 \mathrm{DS}$ would result in vision of approximately $<=6 / 18$ (methods) $[18,19], 34.8 \%(293 /$ $841)$ of clinic users required spectacles.

\section{Discussion}

This preliminary study has identified a high proportion of uncorrected refractive error in homeless people, pointing to a need for provision of regular eye examinations and refractive correction. The spectacles and lenses provided by VCHP are of good quality. The frames and ready readers are donated by Specsavers. Lenses are also donated and glazed free of charge by Essilor, Hoya, Shamir, Kent Optic, Horizon Optical and Caledonian Optical and take between 1-2 weeks to be made up. Approximately $80 \%$ of those prescribed spectacles will collect them (personal communication).

\section{Gender}

The sample used in this study is consistent with studies on homeless people carried out in North America in that a greater percentage of individuals were male. Our sample of homeless people seeking eye care comprised

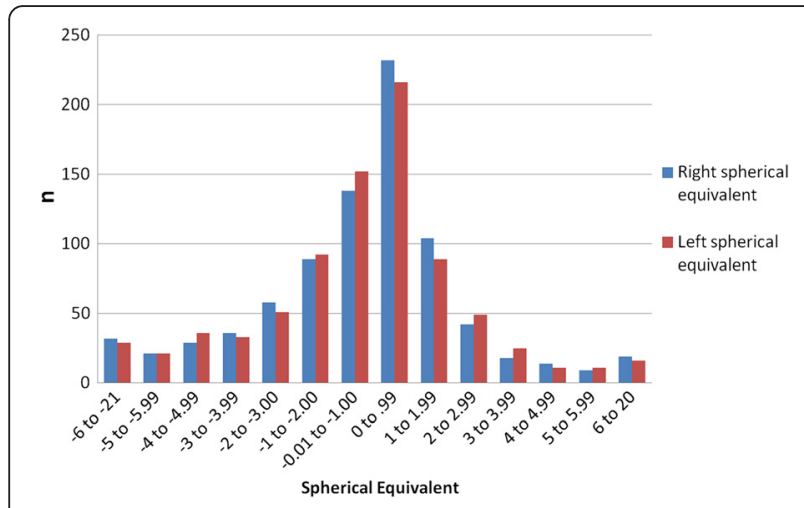

Fig. 2 Spherical equivalent for right and left eyes for all in the sample
$79.1 \%(n=903)$ males, which is comparable with the North American findings of Reeve and Batty (2011) and Kleinman et al. (1996) who each reported $84 \%$ (225/269) [23] and $70 \%(254 / 363)$ [1] males in populations of homeless people in their respective samples. In the UK general population, $49.1 \%$ are male and $50.9 \%$ are female [24]. However, a 2010 study in Hawaii $(n=127)$ found more balanced rates of males (47\%) and females (53\%) in their sample [25] which is comparable to their population of almost equal gender (50.2 \% vs' $49.8 \%$ ) [26]. This finding might be a reflection on the small sample size but it could also perhaps suggest that generalisations between different countries and continents is not easy or necessarily valid because other factors including ethical and cultural differences and different health care infrastructures may also play a role.

\section{Age}

The mean age for our sample shows that on average, the sample was older than for the statutory homeless. This may reflect that our clinic did not accept patients of 18 years or less, and that reading difficulties due to presbyopia (59.9\% of all prescriptions issued in our study included a reading prescription) are an incentive for older homeless people to attend for an eye examination. The Hawaii study sample had a mean age of 35 (range 7-68) [25]. Studies in Los Angeles [27] and Baltimore [28] also included those under 18. The inclusion of children and young people under 18 in these other studies limits to some extent the scope for comparison between those studies and this sample.

The charityhas a chaperone policy to enable them to see $<18$ year olds. The chaperone service ensures that a member of staff is present as well as a parent or guardian. To date, four Syrian refugees have been seen under this new system.

\section{Ethnicity}

Ethnicity population figures show $87.9 \%$ of the UK population to be classified as 'white' [29]. Our sample of homeless people has $80.5 \%$ of individuals classified as 'white', which is comparable to rates in the normal population. 'Asian' people are slightly under-represented at 
$4 \%$ compared to $5.9 \%$ in the normal UK population while the percentage of 'black' people in our sample is $9.9 \%$ which is comparatively high when compared to the UK population at $2.9 \%$ [29].

There are differences, however, when judging this sample's ethnicity against the nationality breakdown provided by National Statistics collected on statutory homeless people and rough sleepers. The data collected on statutory homeless people show $65 \%$ 'white', $15 \%$ 'black', and $7 \%$ 'Asian' [30]. By comparison, our sample has more 'white' people and fewer 'black' and 'Asian' people. This may be a reflection of the EU free movement with more Europeans entering the UK. However, with such a large percentage of patients not having ethnicity details recorded $(417 / 1,141)$, the data is less reliable than it could be.

\section{Visual function}

The prevalence of myopia found within this population of homeless people was $37.0 \%$. This is at the high end of the range compared to rates previously found for the US population of between $16.8 \%$ and $33.1 \%$ [31]. The studies analysed by Pan et al. were conducted in normal populations and covered the whole population to include non-spectacle wearers [31]. This makes it difficult to compare these findings to the sample used in this study, as this sample is from a homeless population who may have been driven to attend by their need for spectacle correction. As a result, the individuals with visual problems may be more likely to attend than individuals with no obvious visual problems.

The prevalence of hypermetropia greater than +1DS found within this study was $21.0 \%$. A study of Americans between 40 and 80 years of age found prevalence rates of $9.95 \%$ of hyperopia $>=+3$ DS [32]. Our sample had a $7.1 \%(60 / 841)$ prevalence over $>=+3 \mathrm{DS}$ and appears comparable.

Using previously determined criteria that an uncorrected refractive error of $<=-1 \mathrm{DS}$ and $>+5 \mathrm{DS}$ would result in presenting vision $<=6 / 18[18,19], 34.8 \%(293 /$ 841) of the homeless people using VCHP would require a refractive correction. It is known that homeless people are a transient population who have difficulties accessing appropriate medical care $[7,9,33]$ due to being unable to provide a permanent address [16, 34]. Whilst homeless people can access GP services via an "immediately necessary" route, onwards referral requires a permanent address. It is therefore not unreasonable to assume that the same issues also apply to eye care. Whilst it is possible in the UK to have free eye examinations and spectacles, the problem of providing a permanent address still arises with the GOS forms. The charity VCHP was set up in 2003 because homeless people were unwilling or unable to access mainstream services through the NHS. The cost of an eye test, if not eligble for an NHS funded eye test, and even a small cost for spectacles can prevent homeless people from being able to access refractive correction [17]. VCHP provide a comprehensive eye examination by a qualified optometrist as would be conducted in high street practice e.g. patients are dilated if clinically indicated and the Skylight Clinic used in this study also has a fundus camera available. Each clinic is attached to a homeless GP service should a referral be necessary. In addition, the charity VCHP provides spectacles free of charge and can also provide a selection of hand magnifiers (which do not require batteries) donated by the RNIB.

One difference between the VCHP clinics and the services offered on the high street is that there is limited potential for repeat visits. On the high street, it is best practice to provide a recall date. VCHP have made the decision that offering a recall date/follow up appointment perpetuates the problem by encouraging people to return to its clinics. The ideal situation is for people to be rehabilitated back into the community so they can obtain housing, jobs etc. Their future care would therefore be back in mainstream high street practice.

Our findings that $34.8 \%$ of homeless people require a spectacle correction is consistent with the findings of Baggett et al. (2010) who report $41 \%(378 / 966)$ of their sample had an unmet need for spectacles [7]. The study by Barnes et al. (2010) in Hawaii reported that two thirds of their sample was uncertain how to obtain spectacles $(66.7 \%)$ or where to access eye care $(48.8 \%)$ [25]. However, there is no information provided about how many of these actually needed a spectacle correction. It is well known that something as simple as spectacle correction can impact upon a person's quality of life $[13,22]$ and that the provision of eye services and free spectacles can improve this $[11,14]$.

\section{Limitations}

The study data are limited to refractive error and demographic data on the sample population. Other data, such as data on ocular pathology and eye movements, were not available via the patient files. New patient records being introduced in the clinic will facilitate more complete data collection in future studies on this population.

Despite the limitations of this study, it still remains the best data set gathered to date on the visual requirements of homeless people in the UK. Whilst other studies have attempted to study this group in other countries, some have found similarities with our data set and many of these studies have encountered similar problems. However, it is important to bear in mind that direct comparisons across the globe remain difficult due to a variety of reasons which could include climate, 
geography, ethical and cultural factors as well as differing social and healthcare infrastructures. Because of these global variations, it is important that baseline data regarding the characteristics of homeless people in the UK are reported so that further work can be undertaken in this vulnerable populations.

\section{Conclusions}

This paper is the first study to investigate the visual problems and needs of homeless people in the UK and sets out a baseline of what to expect in a homeless population in the UK against which further research can be measured. Although similar work has been done in other countries such as North America, this study is unique because the UK is the only country with a National Health Service which provides free health care at the point of access.

This study has identified a high proportion of uncorrected refractive error in this sample, suggesting a need for provision of eye examinations and refractive correction for homeless people. There is scope for expansion of these clinics throughout the UK, and for further data analysis to determine the prevalence of sight threatening disease in this population and in particular to compare with a non-homeless, age-matched population.

To date, there has been no published research on the visual problems and needs of homeless people in the UK. Homelessness is likely to increase due to the current economic climate and so it is important to identify the visual needs of this vulnerable population and devise appropriate strategies to deal with them.

\section{Competing interests}

The authors declare that they have no competing interests.

\section{Authors' contributions}

The analysis and interpretation of the data was initially undertaken by LJK and checked by PJD and CMW. The article was drafted by PJD and LJK and revised by CMW and ECS. All authors contributed to the design of the study and approved the final version of the article.

\section{Acknowledgements \\ The authors would like to express their thanks to Vision Care for Homeless People for allowing us to access the data, The College of Optometrists for sponsoring this work through their Summer Scholarship Scheme, Michael Bowen for his support and advice, Dr. Ahalya Subramanian for her input with the initial summer scholarship application and comments on this manuscript and Dr. Catherine Suttle for her suggestions and comments with the revisions.}

\footnotetext{
Author details

'Division of Optometry and Visual Science, School of Health Sciences, City University London, Northampton Square, London EC1V OHB, UK. ${ }^{2}$ Division of Optometry and Visual Science, School of Health Sciences, City University London, Northampton Square, London ECIV OHB, UK. ${ }^{3}$ Vision Care for Homeless People, c/o Crisis Skylight, 66 Commercial Street, London E1 6LT, UK. ${ }^{4}$ Department of Ophthalmology, Chelsea and Westminster Hospital NHS Foundation Trust, 369 Fulham Road, London SW10 9NH, UK.
}

Received: 29 May 2015 Accepted: 8 February 2016

Published online: 16 February 2016

\section{References}

1. Kleinman LC, Freeman H, Perlman J, Gelberg L. Homing in on the homeless: assessing the physical health of homeless adults in Los Angeles County using an original method to obtain physical examination data in a survey. Health Serv Res. 1996;31:533-49.

2. Kenway P, Palmer G. How many, how much? Single homelessness and the question of numbers and cost. Crisis London. [Online] 2003. Available from: http://www.crisis.org.uk/data/files/document_library/research/ howmanyhowmuch_full.pdf (accessed Jan 2016).

3. QNI Homeless Help Initiative's. Improving healthcare for homeless people-A learning resource. [Online] 2009. Available from: http://www.qni.org.uk/ docs/Section\%20B\%20Module\%201.pdf (accessed Jan 2016).

4. Henley J. The homelessness crisis in England: a perfect storm. The Guardian. [Online] June 25 2015. Available from: http://www.theguardian. com/society/2014/jun/25/homelessness-crisis-england-perfect-storm (accessed Jan 2016)

5. Thames Reach. Homelessness facts and figures. [Online] 2008. Available from: http://www.thamesreach.org.uk/news-and-views/homelessness-factsand-figures/ (accessed Jan 2016).

6. Power R, French R, Connelly J, George S, Hawes D, Hinton T, et al. Promoting the health of homeless people, setting a research agenda. In: Report of Health Education Authority Expert working group, chaired by Robert Power. London: Health Education Authority; 1999.

7. Baggett TP, O'Connell JJ, Singer DE, Rigotti NA. The unmet health care needs of homeless adults: a national study. Am J Public Health. 2010;100(7):1326-33.

8. Bines W. The Health of Single Homeless People. [Online] 1994. Available from: https://www.jif.org.uk/report/health-single-homeless-people (accessed Jan 2016).

9. Riley AJ, Harding G, Underwood MR, Carter YH. Homelessness: a problem for primary care? Br J Gen Pract. 2003;53(491):473-9.

10. ODPM. Addressing the health needs of homeless people. London: Policy Briefing 7; 2004.

11. Maberley DA, Hollands H, Chang A, Adilman S, Chakraborti B, Kliever G. The prevalence of low vision and blindness in a Canadian inner city. Eye(Lond). 2007:21(4):528-33.

12. Page AJ, Ainsworth AD, Pett MA. Homeless families and their children's health problems. A Utah urban experience. West J Med. 1993;158(1):30-5.

13. Ho JH, Chang RJ, Wheeler NC, Lee DA. Ophthalmic disorders among the homeless and nonhomeless in Los Angeles. J Am Optom Assoc. 1997;68(9):567-73.

14. Nia J, Wong D, Motamedinia D. The Visual Acuity and Social Issues of the Homeless Population in Toronto. Toronto: University of Toronto Medical Journal; 2003. p. 84-6.

15. Hwang SW. Mortality among men using homeless shelters in Toronto, Ontario. JAMA. 2000:283(16):2152-7.

16. Crisis. Critical Condition: Vulnerable single homeless people and access to GPs. [Online] 2002. Available from: http://www.crisis.org.uk/data/files/ publications/GP_policybrief\%5B1\%5D.pdf (accessed Jan 2016).

17. Vision Care for Homeless People (VCHP). [Online] 2015. Available from: http://www.visioncarecharity.org/what-we-do/ (accessed Jan 2016).

18. Peters HB. The relationship between refractive error and visual acuity at three age levels. Am J Optom Arch Am Acad Optom. 1961;38:194-8.

19. Harvey B, Franklin A. Routine eye examination. China: ButterworthHeinemann; 2005. p. 84-5.

20. Talbert S, Sole ML. Too much information: research issues associated with large databases. Clin Nurse Spec. 2013;27(2):73-80.

21. Millodot M. Dictionary of Optometry and Visual Science. 5th ed. Oxford: Butterworth-Heinemann; 2000. p. 96-7.

22. Lamoureux EL, Saw SM, Thumboo J, Wee HL, Aung T, Mitchell P, et al. The impact of corrected and uncorrected refractive error on visual functioning: The Singapore Malay Eye Study. Invest Ophthalmol Vis Sci. 2009;50(6):2614-20.

23. Reeve K, Batty E. The hidden truth about homelessness, experiences of single homelessness in England. Crisis, Centre for regional economic and social research. [Online] 2011. Available from: http://www.crisis.org.uk/ data/files/publications/HiddenTruthAboutHomelessness_web.pdf (accessed Jan 2016).

24. Office for National Statistics. 2011 Census: Population Estimates for the United Kingdom, 27 March 2011. [Online] 2011. Available from: http://www. ons.gov.uk/ons/rel/census/2011-census/population-and-householdestimates-for-the-united-kingdom/stb-2011-census-population-estimatesfor-the-united-kingdom.html (accessed Jan 2016). 
25. Barnes JB, Barnes SS, Small CR, Ottoo CS, Bennett MD. Mobile eye screenings for Hawaii's homeless: results and applications. Clin Optom 2010;2:73-7.

26. Infoplease. United States-U.S. Statistics-Census Data. [Online]. Available from: http://www.infoplease.com/us/census/data/hawaii/demographic.html (accessed Jan 2016).

27. Baker RS, Bazargan M, Bazargan-Hejazi S, Calderón JL. Access to vision care in an urban low-income multiethnic population. Ophthalmic Epidemiol. 2005;12(1):1-12

28. Tielsch JM, Sommer A, Witt K, Katz J, Royall RM. Blindness and visual impairment in an American urban population: the Baltimore Eye Survey. Arch Ophthalmol. 1990;108(2):286-90.

29. Office of National Statistics. Population Estimates by Ethnic Group 20022009. [Online] May 18 2011. Available from: http://www.ons.gov.uk/ons/ taxonomy/search/index.html?pageSize $=50 \&$ sortBy $=$ none\&sortDirection $=$ none\&newquery=Population+Estimates+by+Ethnic+Group+20022009\&content-type=publicationContentTypes\&nscl=Population+Estimates (accessed Jan 2016).

30. Statutory homeless: January to March 2012, Housing statistical release June 14th 2012. [Online] 2012. Available from: https://www.gov.uk/government/ collections/homelessness-statistics (accessed Jan 2016).

31. Pan CW, Ramamurthy D, Saw SM. Worldwide prevalence and risk factors for myopia. Ophthalmic Physiol Opt. 2012;32(1):3-16.

32. National Eye Institute. [Online]. Available from: https://nei.nih.gov/eyedata/ hyperopia (accessed Jan 2016).

33. Teruya C, Longshore D, Andersen RM, Arangua L Nyamathi A, Leake B, et al. Health and health care disparities among homeless women. Women Health. 2010;50(8):719-36.

34. North C, Moore H, Owens C. Go Home and Rest? The use of an accident and emergency department by homeless people. London: Shelter p5; 1996.

\section{Submit your next manuscript to BioMed Central and we will help you at every step:}

- We accept pre-submission inquiries

- Our selector tool helps you to find the most relevant journal

- We provide round the clock customer support

- Convenient online submission

- Thorough peer review

- Inclusion in PubMed and all major indexing services

- Maximum visibility for your research

Submit your manuscript at www.biomedcentral.com/submit

) Biomed Central 